MORAES, J.E., DUARTE, K.M.R. e PAULINO, V.T. Cromatografia gasosa na determinação de ácidos graxos voláteis de materiais ensilados. PUBVET, Londrina, V. 5, N. 29, Ed. 176, Art. $1186,2011$.

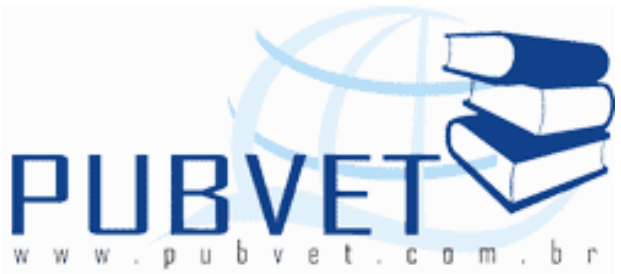

PUBVET, Publicações em Medicina Veterinária e Zootecnia.

\title{
Cromatografia gasosa na determinação de ácidos graxos voláteis de materiais ensilados
}

José Evandro de Moraes $^{1}$, Keila Maria Roncato Duarte ${ }^{2 *}$, Valdinei Tadeu Paulino ${ }^{2}$

${ }^{1}$ Pesquisador Científico - Pólo Vale do Ribeira -APTA-SAA-Governo do Estado de São Paulo- joseevandro@apta.sp.gov.br

${ }^{2}$ Pesquisador Científico -Instituto de Zootecnia -Nova Odessa-APTA-SAAGoverno do Estado de São Paulo. * keila@iz.sp.gov.br

Correspondência: Pós graduação do IZ, Rua Heitor Penteado, 56, Nova Odessa, SP, 13460-000 e-mail: keila@iz.sp.gov.br

\section{Resumo}

O presente trabalho trata-se de uma revisão sobre a utilização da biotécnica Cromatografia Gasosa (GC) como ferramenta para diagnosticar a presença e quantificar os ácidos graxos voláteis (AGVs) e outros ácidos orgânicos de interresse em pesquisas sobre conservação de forragens. Com o intuito de esclarecer de forma simples o que é a cromatografia gasosa, por que esta técnica foi escolhida entre as demais para detecção dos AGVs, quais as suas vantagens. Neste trabalho são abordados também o papel do ácido lático, o processo de ensilagem, porque o milho é o modelo experimental, quando queremos comparar outros ingredientes a serem testados como passíveis também de conservação. Nesta revisão são também abordados os métodos de coleta, armazenamento das amostras a serem analisadas, bem como 
MORAES, J.E., DUARTE, K.M.R. e PAULINO, V.T. Cromatografia gasosa na determinação de ácidos graxos voláteis de materiais ensilados. PUBVET, Londrina, V. 5, N. 29, Ed. 176, Art. 1186, 2011.

necessidade de melhorar a operacionalização do equipamento, pois apesar de sua acurácia, os métodos precisam evoluir para análises precisas e de fácil operação.

Palavras-chave: Cromatografia Gasosa, ácidos graxos voláteis, ácido lático, ruminantes, ensilagem.

\title{
Gas chromatography on the volatile fat acid determination from ensilage material
}

\begin{abstract}
This work is a review about the application of gas chromatographic methods as a tool to identify volatile fat acids and other organic acids on hay and ensilage forage methodologies. It shows the advantages and principles of gas chromatography, empathizing corn as a model for ensilage procedure, latic acid into ensilage protocols, and the sampling methodology for gas chromatography in the way to facilitate the use of the technology into easier procedures for better results with high accuracy and precision.
\end{abstract}

Keywords: Gas Chromatography, volatile fat acids, lactic acid, ruminants, ensilage.

\section{Histórico}

A determinação dos níveis de ácidos graxos voláteis (AGVs) sempre fui uma tarefa complicada e suscetível a muitos erros. Com desenvolvimento das pesquisas e aparecimento de novas técnicas para análise de alimentos destinados a ruminantes, a Cromatografia Gasosa, pôde satisfazer em parte as respostas a uma série de perguntas sobre a correlação dos diferentes ácidos orgânicos formados durante o processo de conservação de forragens conhecido como Ensilagem e qualidade deste material ensilado. 
MORAES, J.E., DUARTE, K.M.R. e PAULINO, V.T. Cromatografia gasosa na determinação de ácidos graxos voláteis de materiais ensilados. PUBVET, Londrina, V. 5, N. 29, Ed. 176, Art. 1186, 2011.

A Cromatografia é um método físico-químico de separação dos componentes de uma mistura, realizada através da distribuição destes componentes entre duas fases que estão em contato íntimo.

Uma das fases permanece estacionária (denominada fase estacionária, FE) enquanto a outra move-se através dela (denominada fase móvel, FM). Separação de misturas por interação diferencial dos seus componentes entre a FE (líquido ou sólido) e a FM (líquido ou gás).

A Cromatografia iniciou no final do século XIX com os seguintes estudos:

-1850 - 1900 - Runge, Goppelsroeder e Schoenbeim.

Separação de misturas de sais e tintas - Início da Cromatografia em Papel- 1889 Uso de sólidos em camada delgada para promover separação de sais inorgânicos. Revelador-HCl (nitrato de prata) e H2SO4 (cloreto de boro)-1905

Separação de misturas de gases usando carvão ativado como adsorvente

-1906 - Tswett -Separação de componentes de extratos de folhas verdes e posteriormente de gema de ovo em diversas bandas coloridas, utilizando coluna de CaCO3.Origem do termo cromatografia, que significa escrever em cores

-1941 - Martin e Synge- Papel de filtro para segurar água, como fase estacionária, e passar uma amostra dissolvida em solvente imiscível em água (técnica de partição). Receberam o prêmio Nobel de Química em 1952.

-1941 Separação de ácidos graxos sobre sílica arrastando-os com $\mathrm{CO} 2$ Início da Cromatografia Gasosa (GC)

-1951 Cromatografia por Bioafinidade. Isolaram anticorpos usando uma coluna com celulose contendo os antígenos apropriados

-1959 Introdução da Cromatografia por Exclusão utilizando peneiras moleculares

-1955 - 1960 - Stahl- Padronizou a técnica de Cromatografia em Camada Delgada

-1962 Cromatografia de Fluído Supercrítico. Primeiro equipamento específico só em 1983

-1970 Fase móvel líquida sob pressão (HPLC), veio cobrir os espaços deixados pela GC 
MORAES, J.E., DUARTE, K.M.R. e PAULINO, V.T. Cromatografia gasosa na determinação de ácidos graxos voláteis de materiais ensilados. PUBVET, Londrina, V. 5, N. 29, Ed. 176, Art. 1186, 2011.

\section{Materiais e Métodos}

Por se tratar de uma revisão, foi necessário o levantamento bibliográfico, bem como associação de elementos e métodos mais utilizados no diagnóstico de ácidos orgânicos e ácidos graxos voláteis(AGVs) em materiais ensilados.

\section{Interpretações de um Cromatograma}

O Cromatograma é a resposta das análises através de um gráfico. Atualmente as resposta geradas são interpretadas por meio de diferentes softwares, o que gera grande aumento da acurácia dos resultados. Dentre as variáveis, o tempo de retenção está diretamente ligado a qualidade da resposta do ensaio. Par cada substância a ser pesquisado existe um tempo de retenção médio e deve ser padronizado. O Cromatograma de qualidade apresenta picos, indicando diferentes compostos, o que traz clareza nos resultados.

As avaliações procuram eficiência, seletividade, resolução e fator de assimetria.

Em um sistema cromatográfico analítico, o CROMATOGRAMA (registro gráfico

Sinal $x$ Tempo de Corrida) é o resultado final do processo de separação cromatográfica:

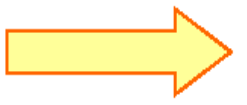

Idealmente, cada analito separado aparece como um único pico cromatográfico, com retenção característica e área proporcional à sua concentração na amostra:

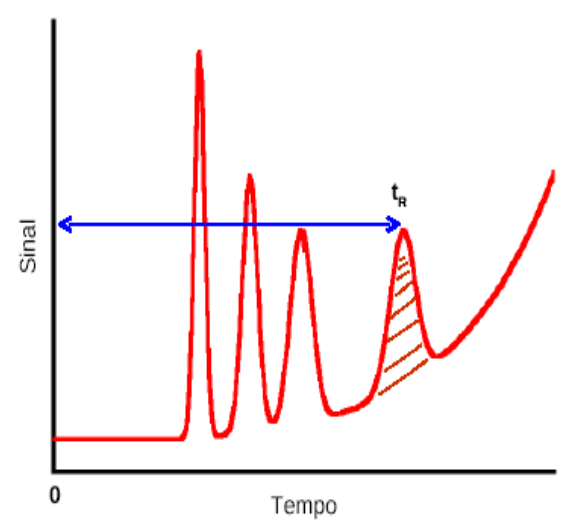

Figura 1 - Registro cromatográfico ( Paschoal et al, comunicação pessoal. 
MORAES, J.E., DUARTE, K.M.R. e PAULINO, V.T. Cromatografia gasosa na determinação de ácidos graxos voláteis de materiais ensilados. PUBVET, Londrina, V. 5, N. 29, Ed. 176, Art. 1186, 2011.

Após a injeção, as moléculas do analito começam a ser arrastadas por ela e se dispersar, distribuindo-se pela coluna segundo o perfil de uma distribuição gaussiana:

$$
y=\frac{1}{\sigma \sqrt{2 \pi}} \exp \left[-\frac{1}{2}\left(\frac{x-\bar{x}}{\sigma}\right)^{2}\right]
$$

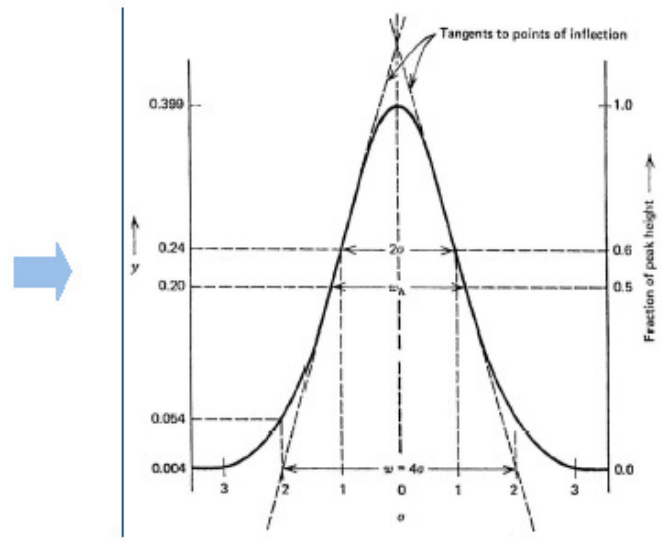

O tempo médio que as moléculas de um analito demoram para atravessar a coluna é o tempo de retenção $t_{R}$. A largura da banda e do pico cromatográficos é função do parâmetro $\sigma$ da distribuição gaussiana associada à eluição $\left(w_{\mathrm{b}} \approx 4 \sigma\right)$

Figura 2 - distribuição gaussiana de injeção de um analito

\section{Aspectos sobre porque escolher a cromatografia á gás na análise de AGVs}

A cromatografia á gás (GC) apresenta as seguintes vantagens:

Rapidez, alta sensibilidade, alta resolução, simplicidade, versatibilidade.

Apesar destas vantagens, esta biotécnica apresenta os seguintes incovenientes: preparação da amostra, a própria amostra e tempo de treinamento para instrumentação e operação do equipamento. (in PASCHOAL, 2009)

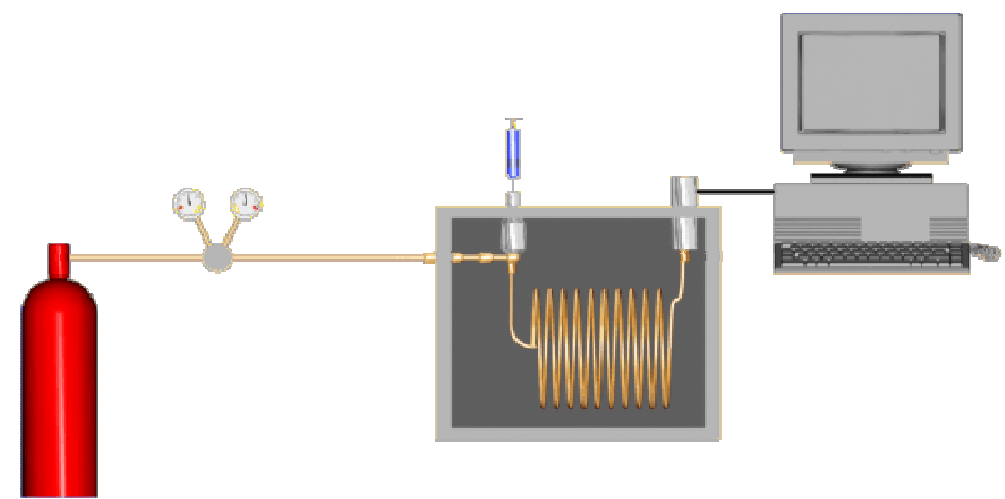

Figura 3 - Esquema de um cromatógrafo a gás. 
MORAES, J.E., DUARTE, K.M.R. e PAULINO, V.T. Cromatografia gasosa na determinação de ácidos graxos voláteis de materiais ensilados. PUBVET, Londrina, V. 5, N. 29, Ed. 176, Art. $1186,2011$.

\section{Aspectos do gás que vai movimentar, sem provocar alterações na amostra.}

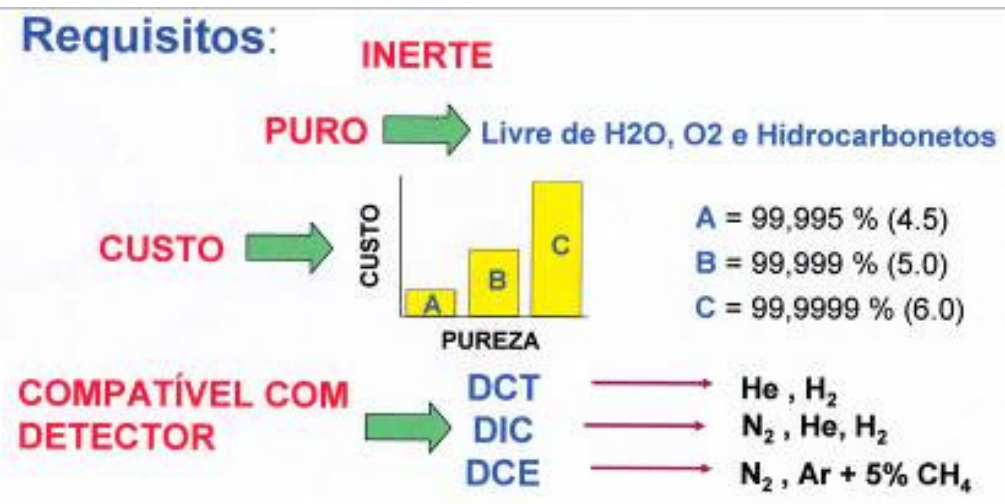

Figura 4 - Requisitos para movimentação do gás

\section{Aspectos do injetor de amostra no sistema.}

O sistema de injeção deve ser rápido, pois se houver atraso na introdução da amostra, pode haver modificações nas bandas (promeve sobreposição de bandas) favorece assimetria e ausência de picos no cromatograma, indicando alterações significativas, incertezas e perda da análise.

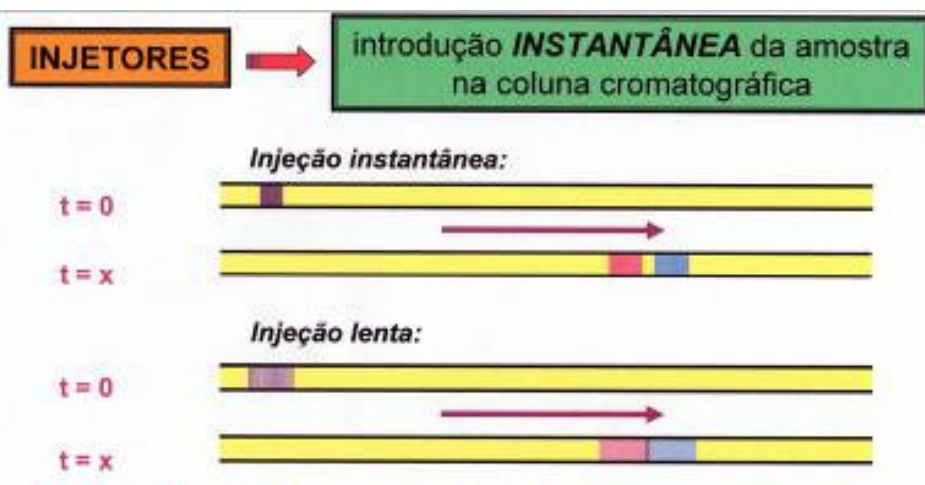

TIPOS: SPLIT/SPLITLESS, on-column e PTV

Figura 5 - Ilustração dos tipos de spliters 
MORAES, J.E., DUARTE, K.M.R. e PAULINO, V.T. Cromatografia gasosa na determinação de ácidos graxos voláteis de materiais ensilados. PUBVET, Londrina, V. 5, N. 29, Ed. 176, Art. $1186,2011$.

\section{Aspectos sobre a temperatura de corrida do sistema}

A temperatura deve ser submetida uma Programação linear, pois o comportamento de diferentes compostos pode interferir nos resultados. Por exemplo, compostos com moléculas mais leves, podem se agrupam em um único pico, quando submetidos a temperaturas mais altas, o que gera erro na interpretação. Compostos mais pesados podem gerar assimetrias e também dificuldades no diagnóstico dos resultados.

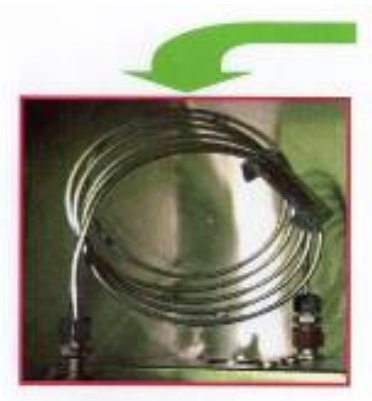

EMPACOTADA

$$
\begin{gathered}
\varnothing=3 \text { a } 6 \mathrm{~mm} \\
\mathrm{~L}=0,5 \mathrm{~m} \text { a } 5 \mathrm{~m}
\end{gathered}
$$

Recheada com sólido pulverizado (FE sólida ou FE líquida depositada sobre as particulas do recheio)

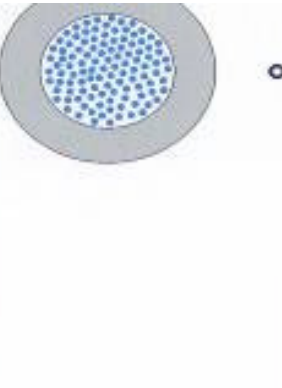

$$
\begin{gathered}
\text { CAPILAR } \\
\varnothing=0,1 \text { a } 0,5 \mathrm{~mm} \\
\mathrm{~L}=5 \mathrm{~m} \text { a } 100 \mathrm{~m} \\
\text { Paredes internas recobertas com } \\
\text { um filme fino de FE liquida ou } \\
\text { sólida }
\end{gathered}
$$

\section{Figura 6- Tipos de colunas}

\section{Aspectos sobre os detectores de compostos}

Podemos relacionar os mais importantes:

\section{-Detector por Condutividade Térmica(TCD) Variação da condutividade} térmica do gás de arraste.

A taxa de transferência de calor entre um corpo quente e um corpo frio depende da condutividade térmica do gás no espaço que separa os corpos. Se a condutividade térmica do gás diminui, a quantidade de calor transferido também diminui - o corpo quente se aquece. 
MORAES, J.E., DUARTE, K.M.R. e PAULINO, V.T. Cromatografia gasosa na determinação de ácidos graxos voláteis de materiais ensilados. PUBVET, Londrina, V. 5, N. 29, Ed. 176, Art. 1186, 2011.

Aplicações: Separação e quantificação de compostos que não geram sinal em outros detectores (gases nobres, gases fixos).

-Detector por Ionização em Chama (FID) Íons gerados durante a queima dos eluatos em uma chama de $\mathrm{H} 2+$ ar.

-Detector por Captura de Elétrons (ECD) Supressão de corrente causada pela absorção de elétrons por eluatos altamente eletrofílicos.

\section{4.Ácidos Graxos Voláteis}

Os Ácidos Graxos Voláteis interferem diretamente na qualidade da forragem a ser consercada, os AGVs de maior importância são:

o ácido acético (do latim acetum, azedo), $\mathrm{CH}_{3} \mathrm{COOH}$, oficialmente chamado ácido etanóico, é um ácido carboxílico (especificamente, um ácido monocarboxílico), saturado e de cadeia aberta. Em sua forma impura, é popularmente conhecido como vinagre. Quando ele está livre de água é conhecido como ácido acético glacial. É conhecido por ser um ácido fraco, corrosivo, com vapores que causam irritação nos olhos, ardor no nariz e garganta e congestão pulmonar. Um reagente químico importante e largamente utilizado na industria química, usado na produção de politereftalato de etila (PET). (in LIDE,2007).

O ácido butanóico (ou ácido butírico) é um ácido monocarboxílico, saturado, de cadeia aberta, com fórmula molecular $\mathrm{C}_{4} \mathrm{H}_{8} \mathrm{O}_{2}$, massa molecular 88 $\mathrm{u}$, e de formula estrutural $\mathrm{CH}_{3}-\mathrm{CH}_{2}-\mathrm{CH}_{2}-\mathrm{COOH}$. (in $\mathrm{LIDE}$,2007).

O ácido propanóico conhecido usualmente como ácido propiônico ou ácido propílico, $\mathrm{C}_{3} \mathrm{H}_{6} \mathrm{O}_{2}$, massa molecular $74 \mathrm{u}$, é um ácido monocarboxílico, saturado, de cadeia aberta, que apresenta fórmula estrutural: $\mathrm{CH}_{3}-\mathrm{CH}_{2}-$ $\mathrm{COOH}$ (in LIDE,2007). 
MORAES, J.E., DUARTE, K.M.R. e PAULINO, V.T. Cromatografia gasosa na determinação de ácidos graxos voláteis de materiais ensilados. PUBVET, Londrina, V. 5, N. 29, Ed. 176, Art. 1186, 2011.

O ácido láctico ou lático ( do latim lac, lactis, leite), é um composto orgânico de função mista ácido carboxílico - álcool que apresenta fórmula molecular $\mathrm{C}_{3} \mathrm{H}_{6} \mathrm{O}_{3}$ e estrutural $\mathrm{CH}_{3}-\mathrm{CH}(\mathrm{OH})-\mathrm{COOH}$. Participa de vários processos bioquímicos, e o lactato é o sal deste ácido.

Estes AGVs, são produtos das reações fermentativas do alimento conservado. A sua formação e qualidade está diretamente ligada a compactação do material ensilado, se neste foi retirado todo o oxigênio do sistema, para evitar reações indesejáveis(multiplicação de fungos, por ecemplo), perda de qualidade do material ou mesmo formação de compostos que pode intoxicar os animais que dele vão servir-se.

A origem e concentração de cada ingrediente ser ensilado interfere nas relaçoes entre os AGVs.Por isso existem materiais com caracteristicas mais interessantes para o processo de ensilagem, pode citar o exemplo do milho que devido suas caracteristicas físicas e químicas, se colhido, compactado e tendo o seu silo fechado em tempo corretos, vai ser um alimento de alta qualidade para ruminantes confinados ou em sistemas de produção que necessitam de suplementação reforçada em períodos de excassez. O milho é o modelo mais usado para camparar com outras possíveis fonte de alimento a serem conservados pelo mesmo método.

O Ácido mais desejável a ser encontrado quando o processo de ensilagem se findou é o ácido Lático, pois confere ao produto resultante poucos odores e maior qualidade deste.(HARGREAVES,1986; Oliveira,2007)

\section{Experimento conduzido com o auxilio da Cromatografia Gasosa}

Trecho Retirado do texto "Características fermentativas de silagens de capim elefante paraíso(pennisetun hybridum) com aditivos, ácidos orgânicos", Zootec2009, Águas de Lindóia ( Paulino et al., 2009) 
MORAES, J.E., DUARTE, K.M.R. e PAULINO, V.T. Cromatografia gasosa na determinação de ácidos graxos voláteis de materiais ensilados. PUBVET, Londrina, V. 5, N. 29, Ed. 176, Art. 1186, 2011.

"A ensilagem é baseada na fermentação lática espontânea, onde em condições de anaerobiose os carboidratos solúveis são fermentados com produção de ácido lático e rápida redução do $\mathrm{pH}$. A produção de ácido lático com redução do $\mathrm{pH}$ cria condições inibitórias da atividade proteolítica das enzimas vegetais e de bactérias indesejáveis. Altas concentrações de ácido acético indicam perdas de matéria seca e de energia, quanto ao ácido butírico, este sempre deve aparecer em pequena quantidade, porque sua presença revela intensa degradação das proteínas, especialmente por atividades clostridiana, com efeitos prejudiciais na qualidade e aceitabilidade da silagem. $O$ uso de alguns aditivos e alternativas para beneficiar o processo fermentativo de silagem de capim-elefante tem demonstrado melhoria na qualidade final das silagens, dentre outros figuram fontes de carboidratos, de materiais com elevados teores de matéria seca e inoculantes enzimobacterianos."

"Nesse contexto, a polpa cítrica destaca-se por seu alto teor de matéria seca e de carboidratos solúveis, alto valor nutritivo e boa aceitabilidade pelos animais, sendo indicada como suplemento para ensilagem de capim-elefante (Faria et al., 1972). Outro produto, o óxido de cálcio, tem sido recomendado para redução da fermentação alcoólica em silagens de cana-de açúcar (Oliveira et al., 2007), entretanto não há praticamente dados sobre seus efeitos em silagens de gramíneas forrageiras tropicais."

"Este trabalho visa determinar os teores de ácidos orgânicos (lático, acético, butírico e propiônico) em silagens de capim elefante Paraíso, mediante a adição de polpa cítrica, aditivo bacteriano comercial e óxido de cálcio."

"Para confecção das silagens experimentais, o corte do capim elefante paraíso foi efetuado aos 100 dias de crescimento, através de corte com segadeira tracionada por trator a uma altura da superfície solo de $10 \mathrm{~cm} \mathrm{e}$ imediatamente colhida e transportada para trituração em ensiladeira regulada para cortes de $1,0 \mathrm{~cm}$. de comprimento. Como silos foram utilizados baldes plásticos com capacidade de $15 \mathrm{~kg}$ de material verde picado, correspondendo a uma compactação de aproximadamente $460 \mathrm{~kg}$ de silagem/m3." 
MORAES, J.E., DUARTE, K.M.R. e PAULINO, V.T. Cromatografia gasosa na determinação de ácidos graxos voláteis de materiais ensilados. PUBVET, Londrina, V. 5, N. 29, Ed. 176, Art. 1186, 2011.

"Decorridos 90 dias de armazenamento, os silos foram abertos e tomadas amostras das quais extraiu-se, através de uma prensa hidráulica $\left(2 \mathrm{kgf} / \mathrm{cm}^{3}\right) 0$ suco das silagens para determinações dos ácidos orgânicos foram realizadas em cromatografia gasosa, segundo método preconizado por Erwin et al. (1961), no laboratório de Bromatologia da Faculdade de Medicina Veterinária/USP/Campus Pirassununga."

"Teores de ácido lático (LAT), ácido acético (ACE), ácido butírico (BUT) e ácido propiônico (PROP) em \% da matéria seca, das silagens de capim Pennisetum hybridum cv. Paraíso."(vide Tabela 1)

"A presença de ácido butírico na massa ensilada é sempre acompanhada de mudanças na qualidade do produto. O efeito prejudicial das bactérias produtoras de ácido butírico é o desdobramento de proteínas. O baixo valor médio de $0,013 \%$ de ácido butírico demonstra o controle da atividade clostridia no processo fermentativo, que prejudica a qualidade e o consumo da silagem. A literatura relata que silagens com até $0,1 \%$ de ácido butírico, poderiam ser consideradas adequadas. Neste sentido, podemos inferir que o tratamento com óxido de cálcio foi inadequado no controle deste tipo de atividade fermentativa, com valores elevados de ácido butírico de 4,79 \%."

"A adição de polpa cítrica ou do aditivo comercial não alterou a concentração de ácido propiônico. Os valores de ácido propiônico obtidos no presente experimento foram baixos (média de 0,02 \%) com uso de polpa cítrica e $0,04 \%$ com uso de aditivo comercial. O tratamento da silagem de capimelefante Paraíso com óxido de cálcio mostrou valores elevados $(1,38 \%)$, diferente $(P<0,05)$ dos demais tratamentos, e que não refletem o perfil típico de uma boa silagem. 
MORAES, J.E., DUARTE, K.M.R. e PAULINO, V.T. Cromatografia gasosa na determinação de ácidos graxos voláteis de materiais ensilados. PUBVET, Londrina, V. 5, N. 29, Ed. 176, Art. $1186,2011$.

Tabela 1 - Fermentação de silagens sob diferentes tratamentos

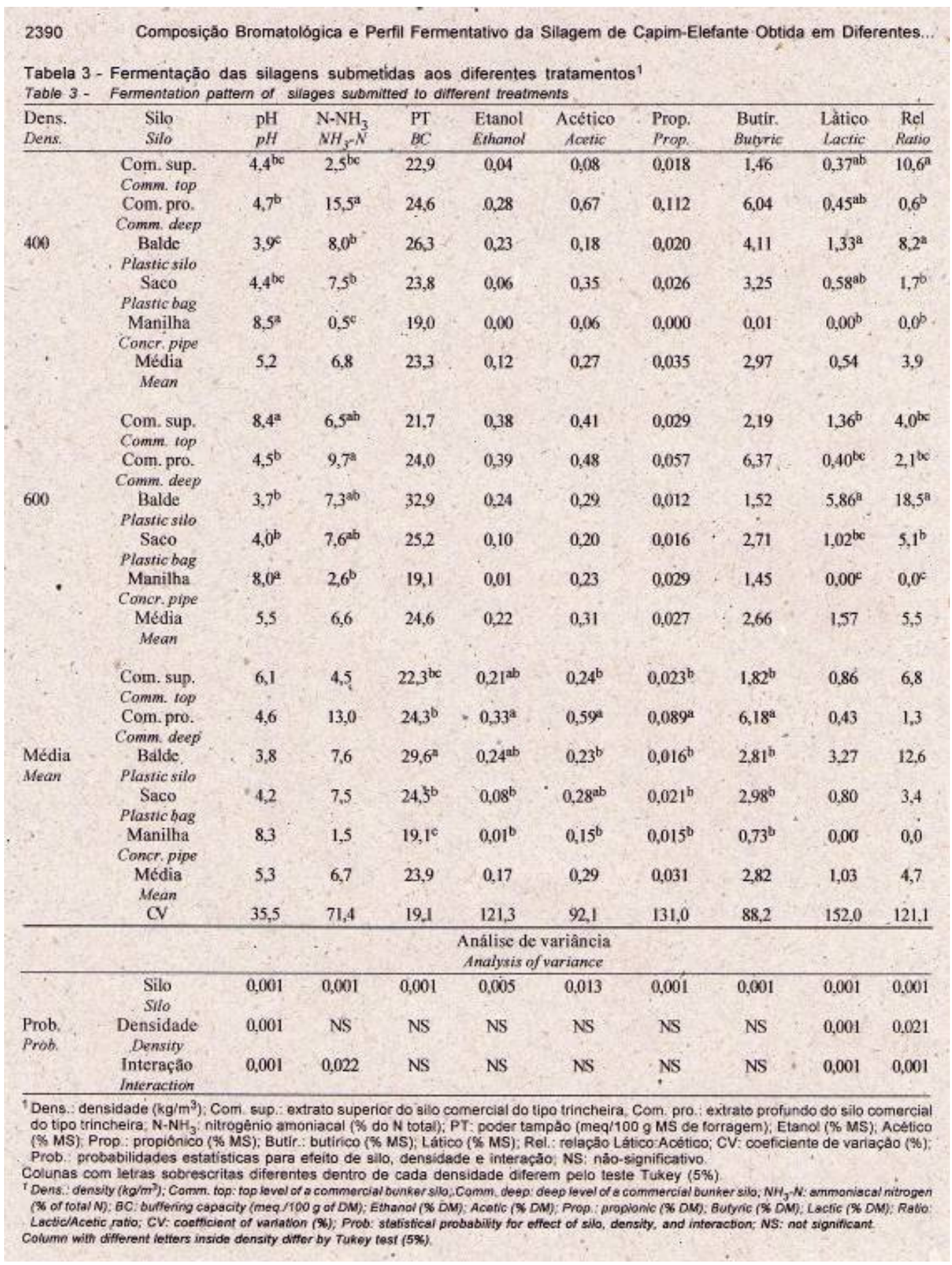


MORAES, J.E., DUARTE, K.M.R. e PAULINO, V.T. Cromatografia gasosa na determinação de ácidos graxos voláteis de materiais ensilados. PUBVET, Londrina, V. 5, N. 29, Ed. 176, Art. $1186,2011$.

A análise do perfil de ácidos orgânicos indica que a adição de 5 a $10 \%$ de polpa cítrica atua como melhorador na qualidade de fermentação na silagem de capim-elefante Paraíso".

"O emprego óxido de cálcio nas silagens de capim mostrou-se ineficiente, com valores inadequados de ácidos orgânicos".

"O aditivo comercial (Silomax) proporcionou um bom padrão de fermentação da silagem, porém seus efeitos foram menores que os obtidos com o uso da polpa cítrica".

\section{Conclusões}

A Cromatografia Gasosa (GC) deve ser empregada para análise de compostos orgânicos voláteis e termoestáveis, de baixa polaridade e baixo peso molecular, combinada com várias técnicas de pré-concentração; pois apresenta detectores extremamente sensíveis.

Por estas características, sua utilização na detecção Ácidos Graxos Voláteis (AGV) presentes no material ensilado, torna-se cada vez mais necessária, bem como pesquisas que facilitem o preparo das amostras a serem analisadas por esta biotécnica.

\section{Referências Bibliográficas}

ANDRADE, S.J.T. Efeito de alguns tratamentos sobre a qualidade da silagem de capim-elefante. Belo Horizonte: Universidade Federal de Minas Gerais, 1994. 73p. Dissertação (Mestrado em Produção Animal) - Universidade Federal de Minas Gerais, 1994.

ASSOCIATION OF OFFICIAL ANALYTICAL CHEMISTS - AOAC. Official methods of analysis.10.ed. Washington, D.C.: 1980. 1015p.

ERWIN, E. S; MARCO, G. J.; EMERY, E. M. Volatile fatty acid analyses of blood and rumen fluid by gas chromatografhy. J. Dairy Sci., 44:1768-1771, 1961.

FERRARI JR., E.; LAVEZZO. W. Qualidade da silagem de capim-elefante (Pennisetum purpurum Shum) emurchecimento ou acrescido de farelo de mandioca. Revista Brasileira de Zootecnia, v.30, n.5, p.1424-1431, 2001.

HARGREAVES, A.B; BUTTERDIACK, N.B; HIRIART, M.L. Comparacion de dos silos experimentales para la investigacion de ensilages. Agricultura Técnica, v.46, n.2, p.185-192, 1986. 
LIDE, David R. (ed.), TAYLOR and FRANCIS. CRC Handbook of Chemistry and Physics. 87.ed (Internet version 2007). Boca Raton, FL. Disponível em: ㅂBCPnetbase. Acesso em: 12 Mai 2007.

OLIVEIRA, A.C.; PIRES, A. J. V.; OLIVEIRA, H.C. et al. Composição nitrogenada de silagens de gramíneas tropicais tratadas com uréia. Arch. Zootec., 56: 15-21, 2007.

PAULINO, V.T.; FERRARI Jr.,E.;POSSETI, R.A. Características fermentativas de silagens de capim elefante paraíso(pennisetun hybridum) com aditivos, ácidos orgânicos, Zootec2009, Águas de Lindóia, 2009.

PEREIRA, J.R.A., ROSSI Jr., P. Manual prático de avaliação nutricional de alimentos. 1.ed. Piracicaba: Fundação de Estudos Agrários "Luiz de Queiroz", 1995. 25p.

RODRIGUES, Paulo Henrique Mazza et al. Composição bromatológica e perfil fermentativo da silagem de capim-elefante obtida em diferentes tipos de silos experimentais e no silo tipo trincheira. R. Bras. Zootec. [online]. 2002, vol.31, n.6, pp. 2386-2392. ISSN 1516-3598.

SILVEIRA, A. C. Produção e utilização de silagens. In: SEMANA DE ZOOTECNIA, 12., 1987. Pirassununga. Anais...Pirassununga: Fundação Cargill, 1987. p. 119-134. 